\title{
The Transportation-Land Use Policy Connection
}

\author{
Gerrit-Jan Knaap ${ }^{a}$ and Yan Song ${ }^{b}$
}

\author{
${ }^{\mathrm{a}}$ Professor and Director \\ gknaap@ursp.umd.edu \\ Suite 1112, Preinkert Field House, Bldg. 054, \\ National Centre for Smart Growth Research and Education \\ University of Maryland \\ College Park, MD 20742 \\ Phone: 301-405-6083 \\ Fax: 301-314-5639 \\ ${ }^{\mathrm{b}}$ Assistant Professor \\ ys@email.unc.edu \\ Department of City and Regional Planning, CB\#3140 \\ University of North Carolina \\ Chapel Hill, NC 27599-3140 \\ Phone: 919-962-4761 \\ Fax: 919-962-5206
}

Prepared for presentation at the Conference entitled,

Access to Destination: Rethinking the Transportation Future of our Region

November 2004

University of Minnesota

Minneapolis, MN 


\section{The Transportation-Land Use Policy Connection}

\section{Introduction}

The discovery of the transportation-land use connection is not new. As Cervero (1991) notes, little has changed since the 1954 publication of Urban Traffic: A Function of Land Use (Mitchell and Rapkin 1954). But the discovery certainly is older than that. The Robber Barons of the $19^{\text {th }}$ Century, for example, probably had some sense of the relationship when they accepted land as payment for constructing the transcontinental railroad. So, most likely, did the Dutch when they purchased Manhattan Island from Native Americans for 24 dollars. In more recent times, recognition of the transportationland use connection rose following the completion of the interstate highway system and the rise of urban sprawl. And as public interest in growth management revived following the 1980 recession, a consensus grew that it was impossible to pave our way out of congestion. As a result, the transportation-land use connection became a central theme of the movement that became known as Smart Growth. At approximately the same time, transportation planning models_-long based on a four-step model that accepted land use

as a given-began to incorporate feedbacks from transportation to land use. LUTRAC, the pioneering effort in Portland, Oregon, to defeat the construction of a circumferential highway is perhaps the seminal application of such models.

In this paper, we explore the transportation-land use policy connection. More specifically, we consider the question: can land use policy be used to alter transportation behavior? The answer is of some importance. If the answer is yes, then there is hope that land use policies can be designed and implemented that will bring some relief to the gridlock and complex transportation problems facing US metropolitan areas. This is the underlying assumption behind most smart growth policy reforms. If the answer is no, then land use policy may still be important, but is not likely to play an important role in resolving transportation issues. 
We proceed as follows. First we offer a schematic that identifies necessary conditions for land use policy to play a role in addressing transportation issues. Specially, we argue that for land use policy to play an effective role, three conditions must hold. First, land use must be able to alter transportation behavior. Second, transportation infrastructure must not fully determine land use. Third, the condition on which we consider most extensively, land use policy must significantly and constructively affect land use. After presenting the schematic, we consider the evidence on each of these conditions. Based on our review of the evidence, we conclude that land use policy can play an effective role in addressing transportation issues, but that the role is likely to be small, often counter productive, and most effective at the neighborhood scale.

\section{A framework for analysis}

In this paper we focus not on the transportation-land use connection, but on the transportation-land use policy connection. Thus land use in our analysis plays an intermediary role. That is, for land use policy to affect transportation behavior, not only must land use affect transportation behavior, but land use policy must affect land use. And for land use policy to affect land use, land use must not be fully determined by transportation infrastructure. Our logic is illustrated in Figure 1 below. In Figure 1, transportation infrastructure and land use policy in some combination affects land use, which in turn affects transportation behavior. Clearly this schematic ignores many important factors, and fails to consider the feedback between land use and transportation that we have now come to recognize. Still it provides structure for our argument and helps isolate key issues.

Transportation Infrastructure $\rightarrow$

$$
\text { Land Use } \rightarrow \quad \text { Transportation Behavior }
$$

Land Use Policy

Figure 1. Analysis Framework 


\section{The land use-transportation behavior connection}

For land use policy to affect transportation behavior, land use must affect transportation behavior. Fortunately, this relationship has been the subject of considerable research over the last two decades, motivated in large by the quest to lower automobile travel through urban design. The research has been greatly facilitated by the rapid rise in GIS technology and by new, innovative approaches of capturing travel behavior (such as global positioning recording instruments, accelerometers, and digital travel diaries). As a result, we are now able to capture features of the landscape and patterns of travel in ways unimaginable just a few years ago. The literature on this subject has grown large, diffuse, and difficult to synthesize-even though the subject is now the focus of several good review articles and books. Yet this voluminous literature features more argumentation than consensus. For our purposes this is not all bad, since it provides us the opportunity to frame the evidence in a manner that supports our argument.

As Crane (1999) demonstrates, much of the research on the influence of land use on transportation behavior focuses on the relationship between outcome measures of transportation behavior (total travel, trip generation rates, car ownership, mode choice, and length of journey to work) and measures of urban form (density of population and employment, land use mix, street and sidewalk circulation patterns, and jobs-housing balance) each measured at the trip origin, trip destination, and points along the trip route. Again, the primary interest is in finding ways to reduce travel in cars. After a careful review of the evidence, Crane offers a conclusion quite similar to the proposition offered by Cervero (2002): high density, a mixture of land uses, more open circulation patterns, and pedestrian-friendly environments are all associated with less travel by car. Similar conclusions are drawn by Frank et al. (2003), who also highlight the importance of thresholds and interactive effects.

But as Crane cautions, these results offer very little of use for designing land use policy. Not only is most of the research plagued with problems of endogeneity - that is, those who choose to live in high density, mixed use, pedestrian friendly environments are 
probably predisposed to less automobility_but most of the work also fails to address both the benefits and opportunity costs of high intensity urban environments. Perhaps many would trade pedestrian accessibility for large houses and private open space; but many more would not. Further, nearly all the research is based on data and analyses at the neighborhood level. From this it is difficult to extrapolate to cities or entire metropolitan levels.

Our review of research in this area leads us to the following conclusions. First, there does appear to be a trade off between high intensity urban living and automobility. Thus it appears possible to design neighborhoods in ways that reduce automobile travel. Still the effects are marginal and may lead to greater concentration of congestion and air quality degradation. Further, there are many who would choose not to live in such environments even if forced to bear the full social costs of driving a car. Thus there indeed seems to be a land use-transportation behavior connection and we know how this relationship works at the neighborhood scale. We still don't know much, however, how this operates at a regional scale, or how to manage land use so as best to serve the interests of those who would choose intense urban living over automobility as well as those who would choose otherwise.

\section{The transportation infrastructure-land use connection}

For land use policy to serve as an effective means of shaping transportation behavior, land use cannot be fully determined by transportation infrastructure. At one level the proposition seems easily dismissed. Land use is determined in part by history, land ownership patterns, topology, culture and many other factors besides transportation infrastructure. But the question here is more subtle and perhaps best illustrated by example. If investments in light rail and light rail stations lead by themselves to complementary land uses around light rail stations, then there is little need for land use policy to accomplish the same. Thus the question is: do investments in all forms of transportation infrastructure lead to appropriate configurations of land uses in the absence of intervening land use policy. 
Like the effects of land use on transportation behavior, the effects of transportation infrastructure on land use are complex and contentious. To oversimplify, the literature has focused primarily on two questions: do investments in roads and highways lead to development patterns widely characterized as sprawl and do investments in public transit lead to transit-oriented development? Once again, despite volumes of research, the evidence on both questions is decidedly mixed, and leaves plenty of room for interpretations that support underlying predispositions.

The proposition that the extension of highways leads to urban decentralization and low-density development patterns is strongly supported by economic theory and common sense. According to economic theory, land rent gradients, and thus urban structure, are largely determined by the trade off between accessibility and transportation costs. Further, highway extension lowers transportation costs, flattens land rent gradients, and causes urban expansion. Common sense suggests that development will take place where roads provide access. Almost no one disputes these general propositions. The disputes centers on issues of causality, elasticity, and significance.

Economic theory and common sense notwithstanding, Guiliano (1989) argues that the effects of highway investments on land use have significantly diminished. Specifically, she argues, "transport cost is a much less important factor than location theory predicts." Her argument is supported by a study by a team of researchers at the Transportation Center at the University of Illinois at Chicago (1998). They found that the decentralization of the Chicago metropolitan area began long before the construction of the metropolitan highway system and would have occurred even without the highways. On the other hand, Boarnet and Houghwout (2000, p. 12), following a detailed review of the literature conclude that: "the evidence suggests that highways influence land prices, population, and employment changes near the [highway] project, and that land use effects are at the expense of losses elsewhere.” After a more recent review, Handy (2002) concludes: 
it is reasonable to conclude that new highway building will enable or encourage additional sprawl to some degree, although to exactly what degree is uncertain and depends on local conditions. However, the converse of this proposition is probably not true: not building more highways will probably not slow the rate of sprawl, at least not much.

Research on the effects of transit on land use patterns has focused almost entirely on rail transit and is somewhat less ambiguous. Again, economic theory and common sense strongly suggests that increased accessibility around rail stations should cause increases in property values and stimulate high-density development. Some empirical research provides supportive evidence of these effects (Huang 1996). But significantly more evidence suggests that these effects are small and perhaps inconsequential without supportive land use policies. Cervero, for example concludes, "LRT can be an important, though unlikely a sufficient, factor in changing land use” (1984, p. 46). Handy (2002) concludes:

The evidence thus supports the proposition that investments in light rail transit will increase densities - but only under the right conditions. These studies point to several important lessons about the conditions under which the proposition will hold: a region that is experiencing significant growth, a system that adds significantly to the accessibility of the locations it serves, station locations in areas where the surrounding land uses are conducive to development, and public sector involvement in the form of supportive land use policies and capital investments. Without these conditions, increased densities are unlikely. With these conditions, increased densities are not assured but they are possible.

The evidence on the effects of highways and transit on land use leads us to the following conclusions. First, it is clear that both highways and transit can have land use impacts. As economic theory suggest, highways can contribute to urban decentralization and transit stations can lead to nodes of high density, mixed use development. Both effects, however, are conditional. Urban decentralization seems to occur even without 
highway construction (Mieszkowski and Mills 1993) and, perhaps, can be mitigated with offsetting land use policies. Transit oriented development, meanwhile, rarely seems to occur without supportive land use policies.

To return to the question of interest, therefore, transportation infrastructure does not appear to fully determine land use. This leaves plenty of room for land use policy to play a role in shaping land use and, perhaps, transportation behavior.

\section{The land use policy-land use connection}

We now turn to the focal question of this paper: does land use policy affect land use? Again, this question would appear on its face to be self evident. Certainly land use policy affects land use. Without government policies that specify the rights of land owners, determine the location of transportation infrastructure, and specify the conditions on which development is allowed to occur, no form of urban development could take place. But again, the question must be considered for its contextual and substantive implications. Can land use policy, as it is formulated and implemented in the United States, shape land uses in ways that significantly alter transportation behavior? We submit that the answer to this question is far from obvious. We address this question at two levels-first at the macro level, in the context of governance frameworks or policy regimes, then at the micro level, focusing on specific types of land use policies.

\section{Policy Regimes}

The notion of policy regimes is a bit ephemeral, especially in the domain of land use. By policy regimes we mean the larger institutional context and statutory framework in which land use policies are imposed. We include in this the definition of property rights, the state statutory framework that govern local land use policy, and the culture and practice of local land use planning. The evidence on which we draw is far from definitive but helps to illustrate larger institutional issues. 
Interesting insights on the effects of institutional context on land use patterns, are provide by Bertaud and his colleagues at the World Bank (2004). Bertaud and his colleagues have examined patterns of urban development in metropolitan areas around the world and considered the impact of land use regimes on urban structure. Some of the results of that work are illustrated in Figure 2 - 4.

Figure 2 illustrates the pattern of urban development in Paris, a city largely constructed in period when land use decisions were shaped by land markets. As shown in the Figure, the density of development in Paris displays the well-known pattern of exponential decay caused, according to economic theory, by declining land prices and corresponding capital-land substitution. Figure 3 illustrates the pattern of urban development in Brasilia, Moscow, and Johannesburg, cities largely constructed during periods in which land use decisions were made without land markets. As shown in Figure 3, the density of urban development in these cities displays quite different patterns than Paris which, according to Bertaud, reflects the absence of market discipline on the relationship between accessibility and land use.

Figure 4, displays the pattern of development in North American, European, and Asian cities constructed under the influence of market forces. As shown in Figure 4, Asian cities, where transportation is dominated by walking and biking, display the steepest density gradients; European cities, where transportation is dominated by transit, have less steep gradients; while North American cities, where transportation is dominated by the car (especially in Atlanta) have the flattest density gradient. Bertaud uses these diagrams to make two points. First, he argues, when allowed to do so, market forces impose a discipline on development patterns that reflect the trade-off between accessibility and urban intensity. Where accessibility is high, land prices are high, and urban densities are high. Further, where market forces dominate, development patterns are largely shaped by the dominant mode of transportation. These arguments suggest that land use policy regimes can and do make a significant difference. 


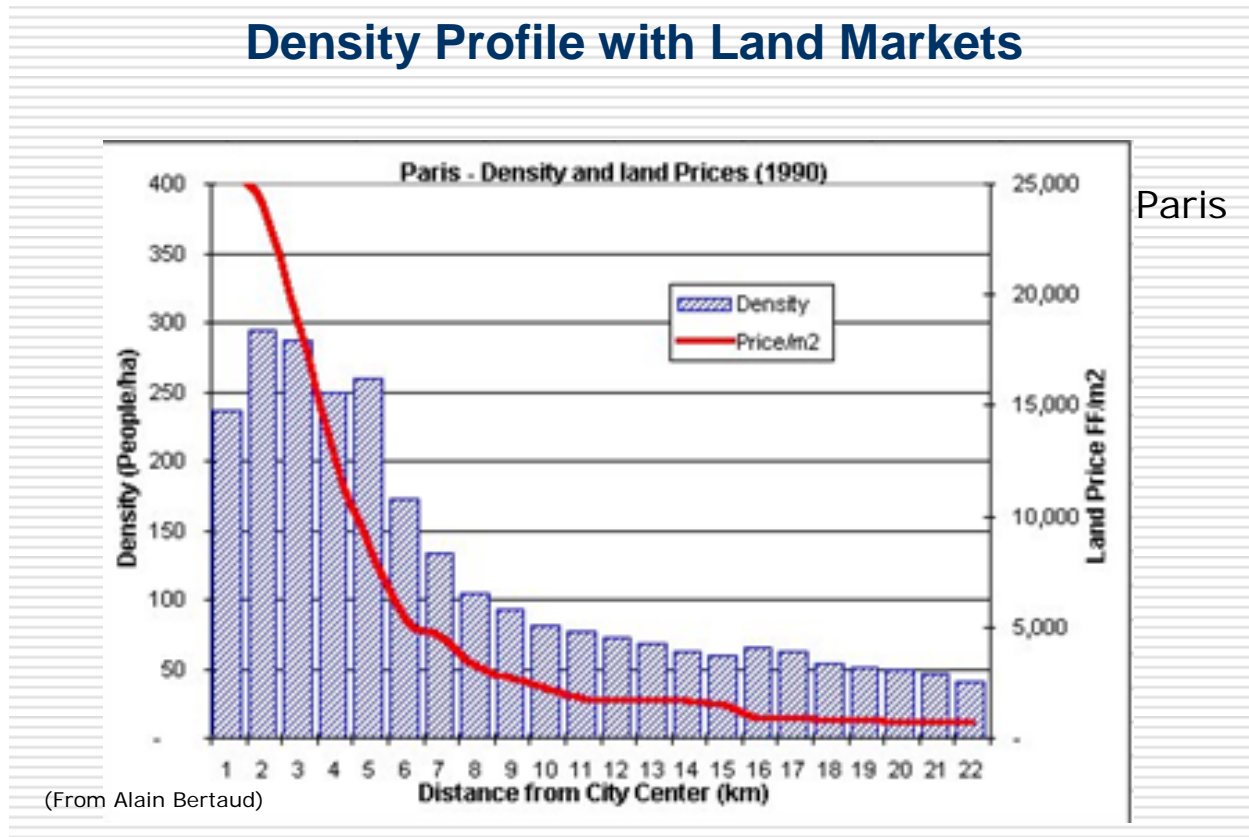

Land use efficiency indicated by high-degree of land-capital input substitution

Figure 2. Density Profile for City of Paris (Bertaud 2004)

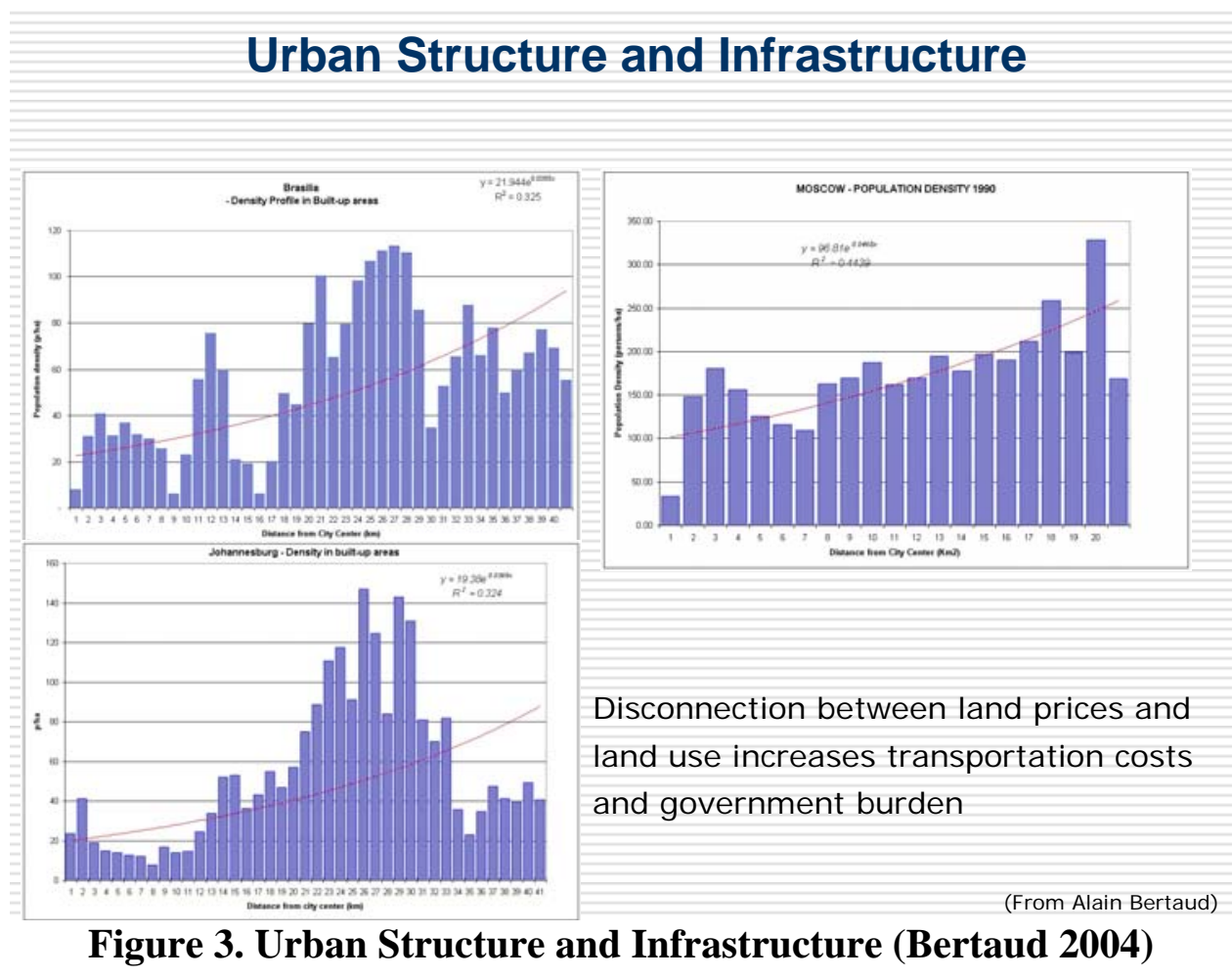




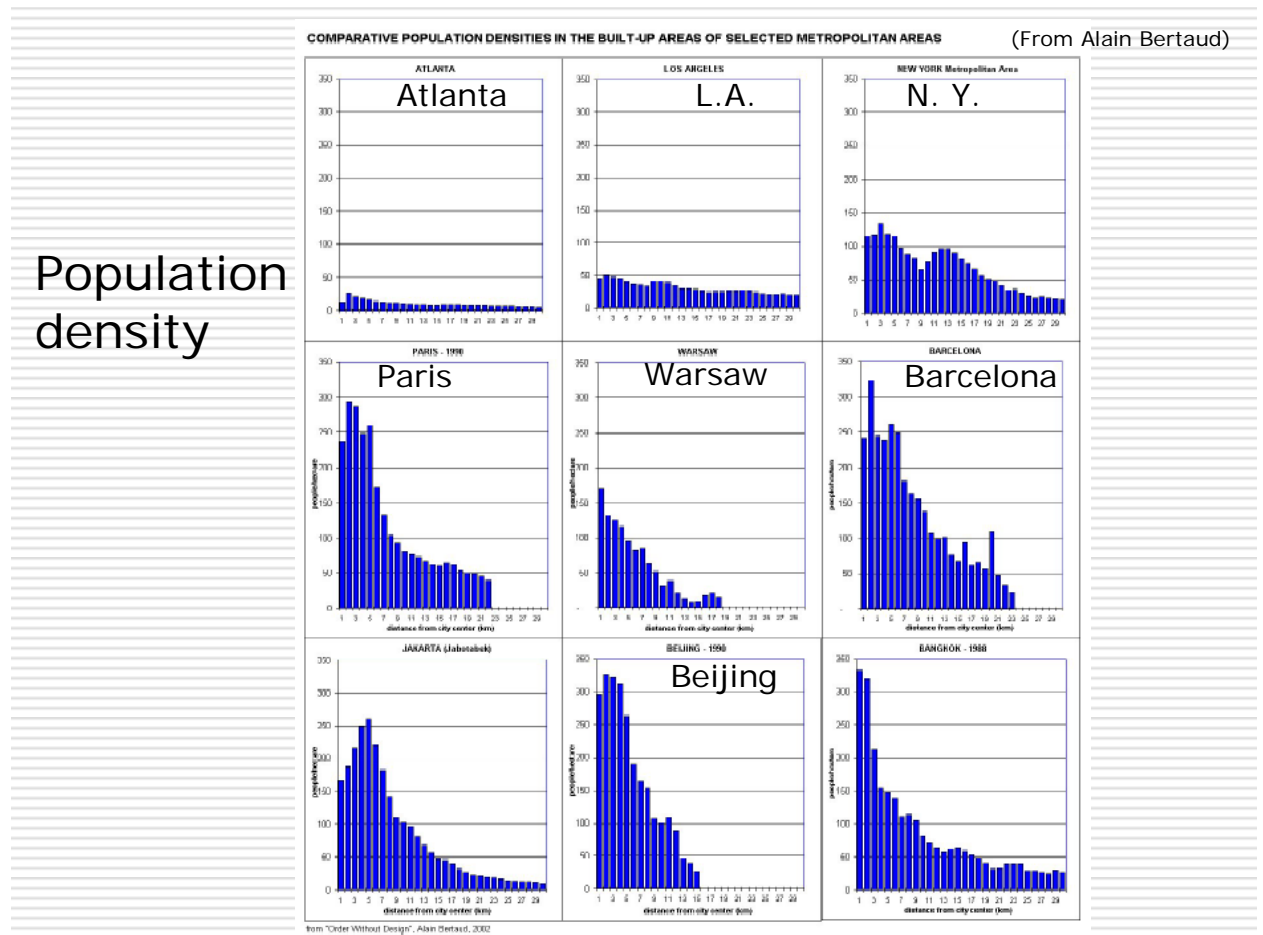

Figure 4. Population Density for Different Cities (Bertaud 2004)

The work by Rolf Pendall on policy regimes provides additional insights. In a series of papers, Pendall (1999, 2000, and 2001) identifies how land use policy regimes differ across the country and shows how differences in land use regimes lead to differences in land use and demographic composition. Based on a nationwide survey of local government planning practices, and using cluster analysis, Pendall identifies eight distinct policy regimes in the United States: Big City, Growth Management, Mitigated Growth Control, Suburban Growth Control, Suburban Sprawl Control, Laissez Faire, Modified Exclusion, Exclusionary Zoning. Then using analysis of variance, Pendall examined the relationship between policy regimes and development density. He finds that between 1982 and 1997, development under Growth Management regimes became significantly denser than under Laissez Faire regimes. Further, Pendall finds that development under Exclusionary Zoning regimes resulted in lower overall densities and, perhaps, the exclusion of racial minorities. This work suggests that land use policies can facilitate more favorable transportation-land use connections, but can also lead to low density development and exclusion. 
These works provide illustrative, if not compelling, evidence that land use regimes can significantly affect land use. The work by Bertaud suggests that land use regimes dominated by market forces creates a pattern of land uses that reflects the influence of accessibility; further, where such accessibility facilitates high-density, such developments will be forthcoming. The work by Pendall suggests that land use regimes dominated by exclusionary interests can lead to low density development and exclusion. Judging by these two sources alone, it appears land use policies—at the macro scale—can both strengthen and weaken the transportation-land use connection.

\section{Policy Instruments}

Research on the effects of specific policy instruments on land use is more voluminous and thus more ambiguous. Policy instruments vary widely in type and strength of implementation. Here we focus on three types of land use instruments: land use regulations, land use plans, and development incentives.

\section{Regulations.}

The literature on land use regulations is large and dominated by economists. Here we consider three types of regulations: zoning, urban growth boundaries, and subdivision regulations. The literature on zoning is by far the most developed. Most of the research, especially by economists, explores the effects of zoning on land and housing prices. If zoning affect prices, economists infer, then zoning affects land use and land allocation. With few exceptions, economists find that zoning does affect land and housing prices. Many economists, however, have argued that zoning follows rather than constrains the market. That is, zoning regulations tend to mimic market forces, thus the effects of zoning on land values may simply reflect the misspecification of an endogenous effect. Still the overriding conclusion of this body of research is that zoning at best does little to alter land use and when it does, it tends to limit development density and do more harm than good. 
With support from the U.S. Department of Housing and Urban Development, a team of researchers at the National Center for Smart Growth (NCSG 2005) are currently exploring the effects of zoning on housing density and single family-multifamily mix. Toward this end, the research team has collected zoning data in GIS format from seven metropolitan areas. The team will then compare actual densities with zoning densities to examine whether zoning constrains housing density and mix. At present the work is incomplete, but a quick examination of the relationship between zoning density and actual density in the Portland metropolitan area provide some insights.

Figure 5 illustrates in three dimensions the existing density in the Portland metropolitan area. Figure 6 illustrates density allowed by zoning. Figure 7 illustrates the difference between existing density and zoned density. As shown in Figure 7, the difference between zoned density and actual density (or available development capacity) is greatest in the city center and in the subcenters of the metropolitan area. Substantial development capacity also exists at Max (light rail) station areas and along major transportation corridors. This clearly reflects Portland's attempts to concentrate development in urban centers and transportation corridors as articulated in its 2040 plan. But it just as clearly it illustrates the difficulty of promoting density using land use policy. Though it is still early in the life of the 2040 plan, it is clear that zoning parcels for high density does not immediately or necessarily lead to higher density development—even when growth is contained within an UGB. 


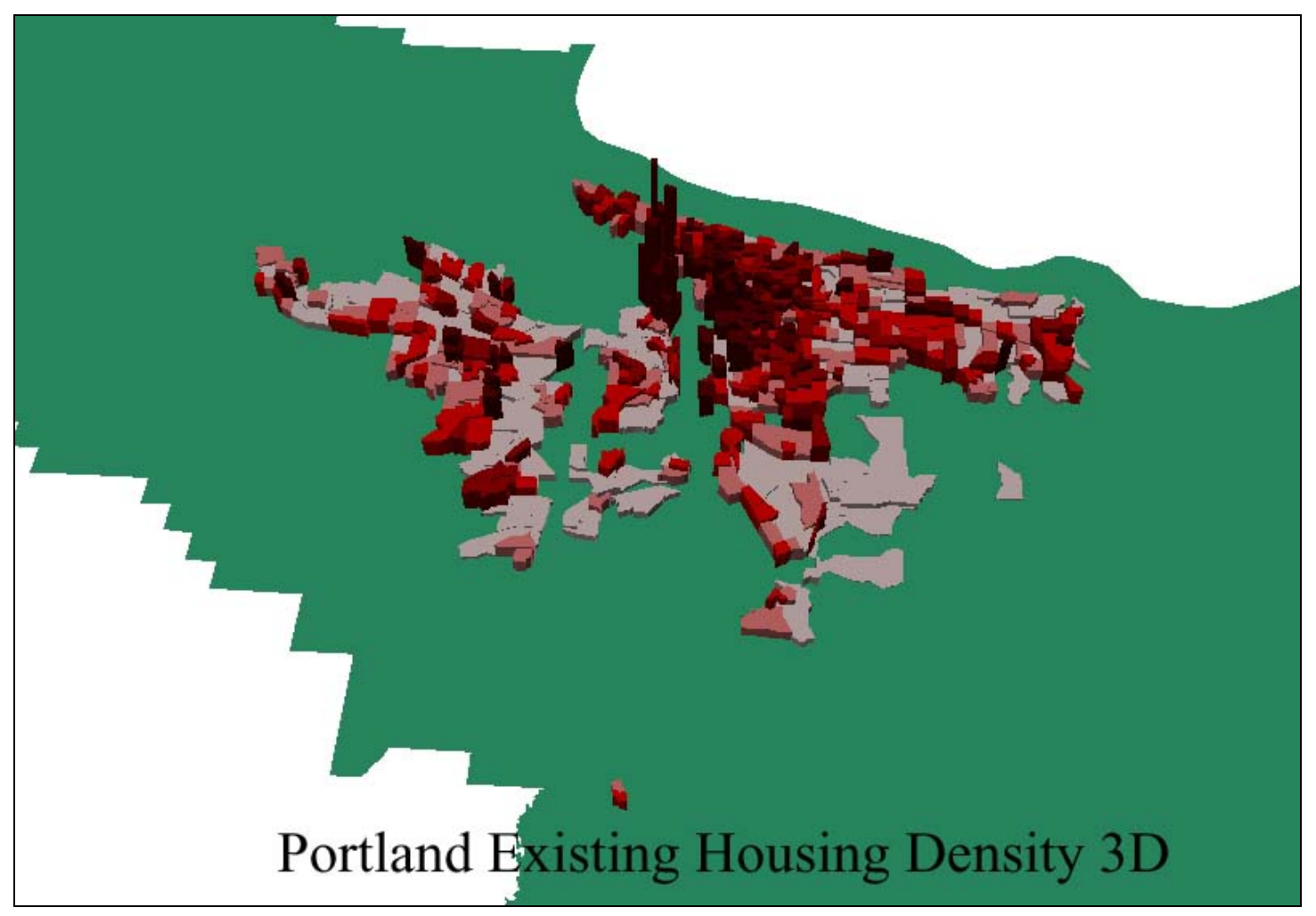

Figure 5. Existing Housing Density in Portland

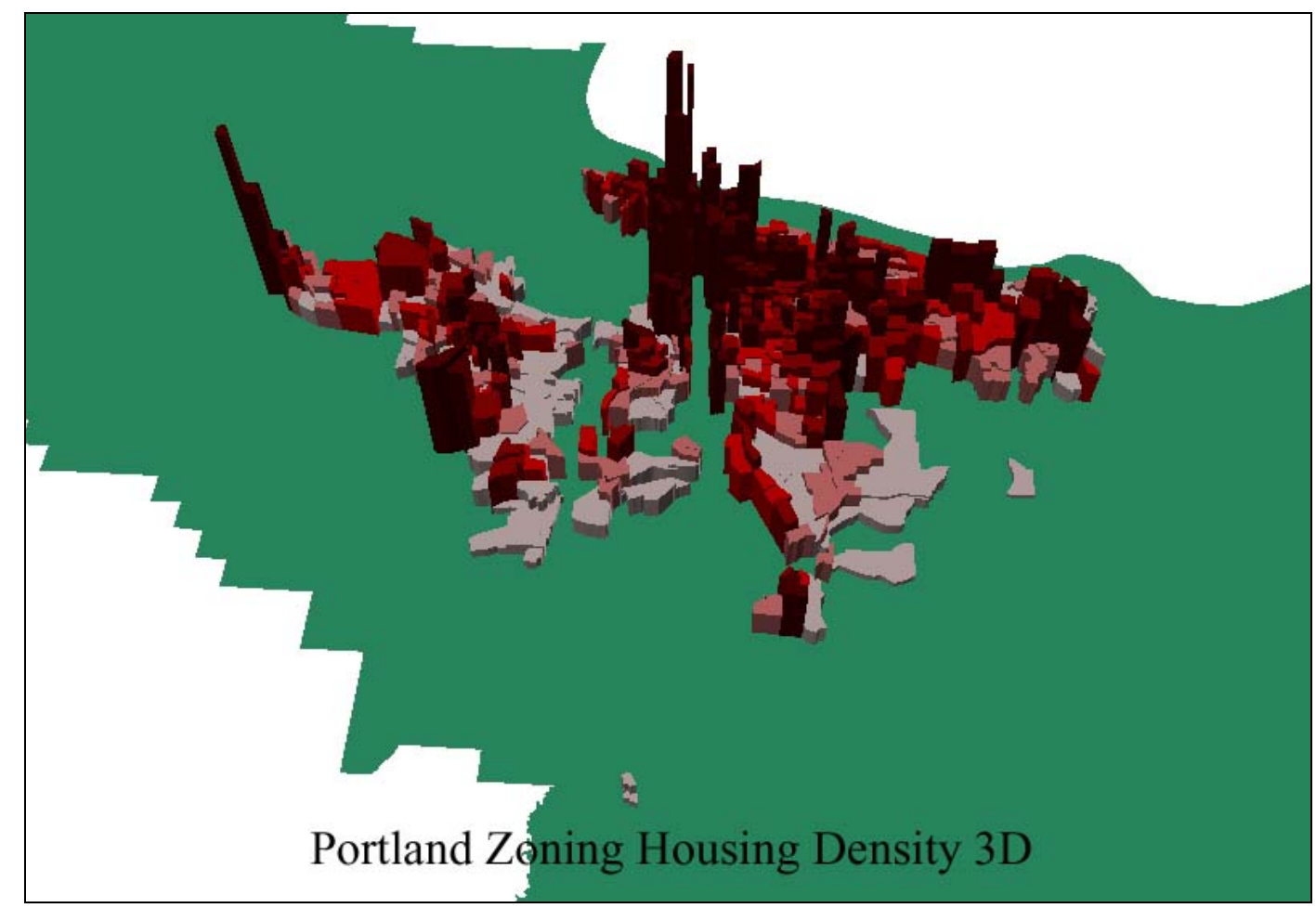

Figure 6. Zoned Housing Density in Portland 


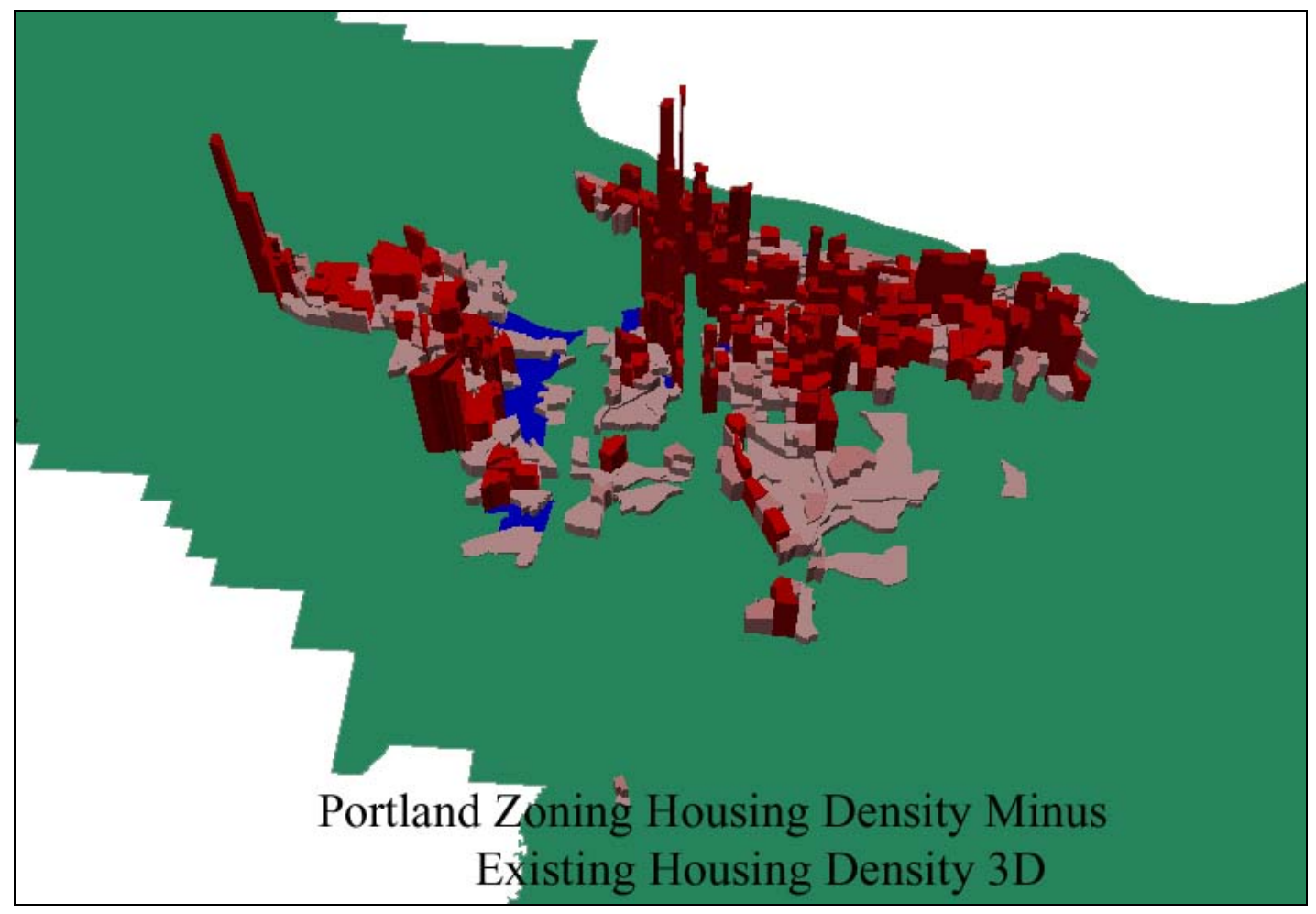

Figure 7. Difference between Existing and Zoned Housing Density in Portland

Research on urban growth boundaries (UGBs) is much less voluminous and dominated by discussion on the effects of Portland's UGB. Long ago Knaap (1985) examined the effects of Portland's UGB on land values on the Oregon side of the metropolitan area. Though the UGB had been in place for only a few years, he found that land values were higher inside than outside the UGB. Corroborating evidence was soon offered by Nelson (1986) in his examination of the UGB in Salem. Since then a debate has raged as to whether Portland's UGB has adversely affected housing affordability or served as an effective tool for managing urban growth (Knaap 2001). Our take on this issue is that Portland's UGB has actually had little effect direct effect on land prices or development densities. Because the UGB must always contain the capacity to accommodate 20 years of growth, we maintain that the UGB has been effective at framing a regional planning effort but has had little effect on the quantity or density of Portland's growth. 
Most of the research on the effects of subdivision regulations is qualitative. Many claim that subdivision regulations impede the development of mixed use, pedestrian friendly neighborhoods. Based on these claims there have been developed several model subdivision regulations and development codes with intent to overcome this impedance. To explore this question, Talen and Knaap (2003) collected zoning codes and regulations from a large sample of cities and counties in Illinois and concluded that such regulations imposed more restrictive requirements on set backs, parking spaces, lot sizes, and street widths than were necessary compared to widely accepted contemporary standards. But the extent to which such standards actually alter development patterns remains largely unexplored.

In a recently published paper Song and Knaap (2004), computed several measures of urban form for Washington County, Oregon, and examined how they changed over time. Though the paper did not specifically focus on subdivision regulations, they noted how local subdivision regulations were shaped by the 2040 plan, the plan prepared by Metro, Portland's regional government. Changes over time in these measures for the entire Portland metropolitan area are illustrated in Figure 8. Figure 8 illustrates the urban form of the "median" TAZ developed in each decade, where the age of the TAZ is determined by the median "year built" attribute of the housing stock and the median TAZ is the TAZ for which the various measures of urban form come closest to the median value of the entire metropolitan area. (For more detail on methods, see Appendix A) As shown, internal connectivity, illustrated by the ratio of red dots (cul-de-sacs) to total dots, was high in the 1940s, fell until the 1970s, and started rising again in 1980. External connectivity, illustrated by the length of the line segments around the edge of the neighborhood, exhibits a similar trend. Single family lot sizes rose from 1940 to 1970 then fell continuously to reach an all time low after the year 2000. As depicted by the mixture of the color of the lots, land use mix has continuously fallen over the same period. A combination of improved proximity to commercial uses and internal street network connectivity has brought increased pedestrian accessibility since 1990. Based on these results Song and Knaap concluded that changes in land use policies in general, and in 
subdivisions regulations in particular, urban form in the Portland metropolitan area had improved at the neighborhood scale but not at the regional scale.

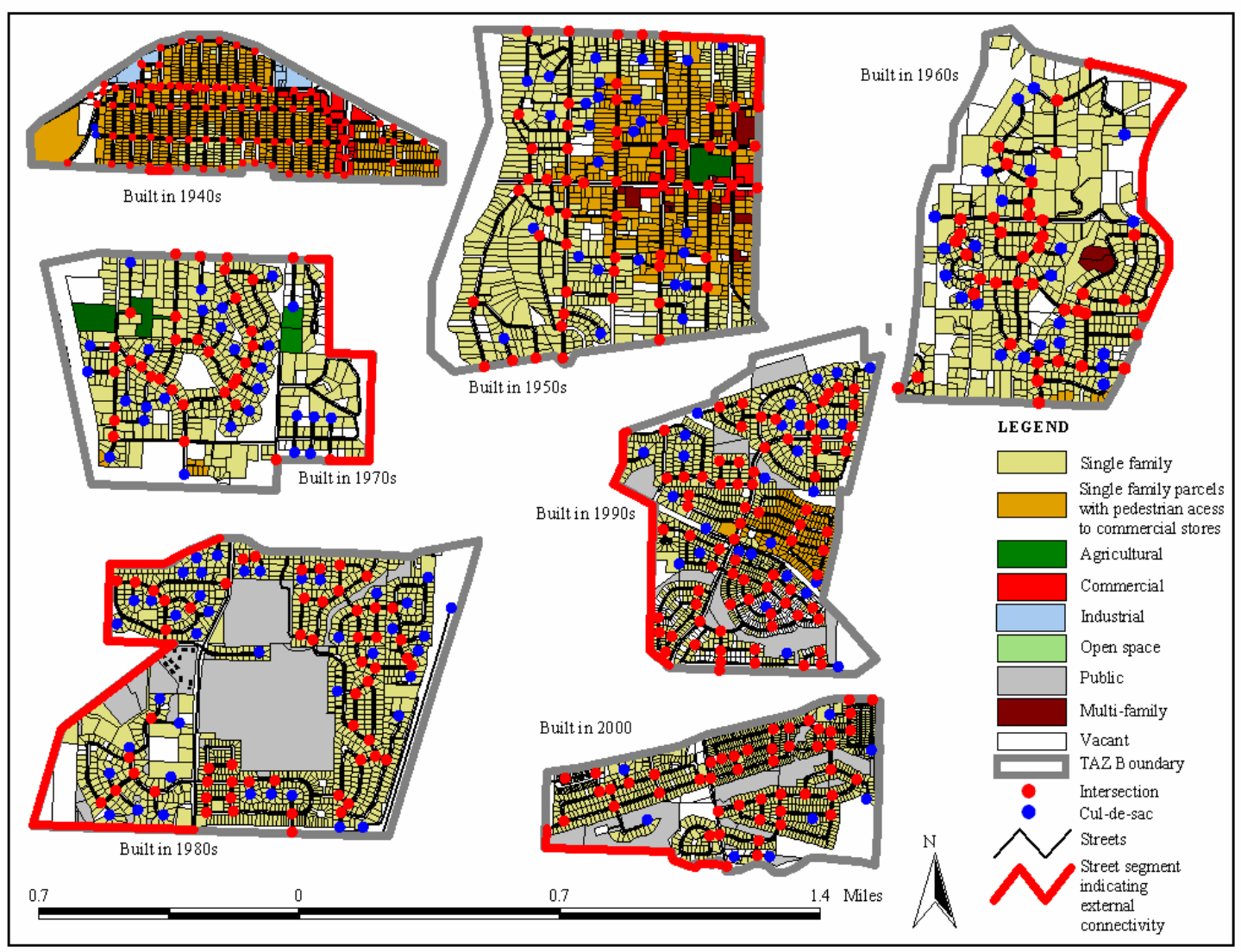

Figure 8. Typical neighborhoods by each decade in Portland metropolitan area

\section{$\underline{\text { Land Use Plans. }}$}

The effect of land use plans on land use is also largely unexplored and inconclusive. The extant literature on the influence of plans largely focuses on the content of plans or on narrow measures of implementation. Alterman and Hill (1978) compared land uses and densities in a plan with eventual development densities and found approximately 66 percent congruence. Talen (1996) examined plans for parks with the eventual size and locations of parks in Dallas, Texas, 20 years later and found a reasonable level of consistency. Connerly and Muller (1993) examined the number of 
times a plan was used in decision making but did not examine how plans affected land use. Others have looked at whether the land market responds to the information contained in plans. Ding, Hopkins and Knaap (2002), for example, examined whether plans for light rail stations in the Portland metropolitan area affected land values before the light rail system began operation. Though the magnitude was small, Ding et al. found that land values did increase within a half mile of the planned station area. Similar results are reported by Ferguson, Goldberg, and Mark (1988), Gatzlaff and Smith (1993), and McDonald and Osuji (1995). These results, we argue, offer evidence that markets respond to the information content in plans and that land values and development patterns would subsequently be affected.

\section{Incentives.}

Research on the effects of incentives on land use has grown in recent years. The use of incentives in place of regulations is an approach pioneered by the state of Maryland. Thus on this subject we focus our comments on policies in Maryland by researchers at the University of Maryland.

Cohen and Pruess (2002) examined the efficacy of Montgomery County’s wellknown transferable development rights program. Under this program development rights in Montgomery County's agricultural reserve could be sold or transferred to areas within the existing urban envelope. Cohen and Pruess found the price of development rights falling over time, the supply of receiving areas diminishing, and the extent to which the programs preserves farmland in doubt. Further, because the program failed to target the most the most fertile soils as sending areas, and failed to provide adequate and timely infrastructure in receiving areas, the popularity of the program has fallen significantly.

Sohn and Howland (forthcoming) examined the effects of Maryland's Priority Funding Areas on investments in sewer infrastructure from 1997 to 2002. According to Maryland's Smart Growth Statutes, passed in 1997, the state will only invest in urban infrastructure inside PFAs. They found that of the total amount invested in sewer 
infrastructure by counties, 25 percent was invested on sewer infrastructure outside PFAs. But of the total amount invested by the state, 29 percent was invested on sewer infrastructure outside PFAs. Most of these investments were used to repair nonperforming septic systems. Still, these findings suggest that even the state is having difficulty conforming to smart growth incentives.

Sohn and Knaap (2002) examined the effects of Maryland's job creation tax credit program (JCTC), which, since 1997, provides greater credits for job creation inside than outside priority funding areas. Using data on job growth in Maryland from 1996 to 2000 and spatial econometric techniques, Sohn and Knaap found that job growth was greater inside than outside PFA's, holding other things constant, but only for jobs in the service sector. Based on these results, they concluded that Maryland's JCTC program can help to concentrate job growth in PFA's but that the contribution of the JCTC program toward such concentration is likely to be small.

\section{Summary}

The above brief and highly selective review of the literature on the effects of land use policy on land use, like the other sets of literature, is highly mixed and subject to interpretation. The literature on land use policy suggests that policy regimes differ significantly with potentially significant effects on land use patterns. Somewhat ironically, though, the studies reviewed here suggest that regimes that rely on market forces are better able to coordinate land use with transportation and that more invasive regulatory regimes in the US can lead to more exclusion and urban sprawl. The literature on specific regulatory instruments provides corroborative evidence. Zoning has been shown to affect land prices and land allocation but the result has generally been lower densities and a limited ability to increase densities. Urban growth boundaries can provide an effective framework of land use planning but also have limited ability to increase urban densities. Subdivision regulations, on the other hand, can affect street network patterns at the neighborhood scale but not at the regional scale. The literature on the

effects of incentives and plans, is no more encouraging. While markets appear to react to 
plans, the reaction is typically small. And based on analyses of smart growth programs in Maryland, TDRs, PFAs, and JCTCs have minor effects on the location of urban development at best.

\section{Conclusions}

In this paper we have offered a brief examination of the transportation-land use policy connection. By selectively drawing on three large bodies of literature we have come to the following conclusions:

- Land use can affect transportation behavior, but the evidence is more compelling on how land use affects transportation behavior at the neighborhood scale than at the metropolitan scale;

- Transportation infrastructure can affect land use but the effects are often small without accommodating, or countervailing, land use policies;

- Land use regimes and regulations can affect land use, but many land use regulations are much more effective at limiting development than increasing densities.

So, to return to the central question: can we use land use policy to shape transportation behavior? Perhaps. At the regional scale we have limited knowledge about how to design transportation and land use policies that meet the needs of those who prefer to live in urban environments without the car and those who prefer to live in suburban environments and with the car. Further, land use institutions in the US are at present-and probably for the foreseeable future-ill suited to design and implement policies at that scale. Thus, success at the regional scale will require regional institutions with the capacity to design integrated land use and transportation plans and the regulatory capacity to assure their implementation.

At the local scale, the obstacles are different though no less formidable. We know what kinds of urban environments lead to less automobile use for those who choose to 
live in them. We also know that we should remove existing policies that preclude the development of such urban environments. The simple removal of regulatory constraints, however, is unlikely to produce adequate results. Further, plans and incentives alone are unlikely to produce adequate results. What we appear to need at the local level is strong regulatory policies, public-private partnerships, or direct public investments in transitoriented development. At the local level the problems are less technical than political. We have the knowledge and the tools. Whether we will generate the political will remains to be seen. 


\section{References}

Alterman, R. and M. Hill, 1978. "Implementation of urban land use plans," Journal of American Planning Association 44(3): 274-86.

American Planning Association, 1998. The Principles of Smart Development. PAS report \#479, Chicago, IL: APA.

Bertaud, A., 2004. The Spatial Organization of Cities: Deliberate Outcome or Unforeseen Consequence. Available at:

http://alain-

bertaud.com/images/AB_The_spatial_organization_of_cities_Version_3.pdf.

Boarnet, M.G. and A. Houghwout, 2000. Do Highways Matter? Evidence and Policy Implications of Highways' Influence on Metropolitan Development. Washington, DC: Brookings Institution.

Cervero, R., 1984. "Light rail transit and urban development," Journal of the American Planning Association 50(2): 133-147.

Cervero, R., 1991. “Congestion relief: The land use alternative,” Journal of Planning, Education and Research, 10(2): 119-130.

Cervero, R. 2002. "Induced travel demand: Research design, Empirical evidence and normative policies,” Journal of Planning Literature 17: 3-20.

Cohen, J. and I. Preuss, 2002. An Analysis of Social Equity Issues in the Montgomery County (MD) Transfer of Development Rights Program, College Park, MD: University of Maryland. Available at: http://www.smartgrowth.umd.edu/research/pdf/TDRequity.text.pdf

Connerly, C.E. and N.A. Muller, 1993. "Evaluating housing elements in growth management comprehensive plans," In Growth Management: The Planning Challenge of the 1990s, ed. J. Stein, 185-199. Newbury Park, CA: Sage.

Crane, R., 1999. The Impacts of Urban Form on Travel: A Critical Review. Working paper, Lincoln Institute of Land Policy, Cambridge, MA.

Ding, C., G.J. Knaap and L. Hopkins, 2002. "Does planning matter? The effects of light rail plans on land values in station areas," Journal of Planning, Education and Research 21(1): 32-39.

Fergusan, B.G., M.A. Goldberg, and J. Mark, 1988. "The pre-service impacts of the Vancouver Advanced Light Rail Transit System on single family property 
values,” In Real Estate Market Analysis: Methods and Applications, edited by J. M. Clapp and S. D. Messner. New York: Praeger.

Frank L.D., P.O. Engelke, and T.L. Schmid, 2003. Health and Community Design: The Impact of the Built Environment on Physical Activity, Washington, DC: Island Press.

Gatzlaff, D.H. and M.T. Smith, 1993. "The impact of the Miami Metrorail on the value of residences near station locations,” Land Economics 69 (1): 54-66.

Guiliano, G., 1989. "New directions for understanding transportation and land use," Environment and Planning A 21: 145-159.

Handy, S., 2002. Smart growth and the transportation-land use connection: what does the research tell us. Presented at New Urbanism and Smart Growth: A Research Symposium, College Park, MD. Available at:

http://www.smartgrowth.umd.edu/events/pdf/HandyPaper2.pdf.

Huang, H., 1996. “The land-use impacts of urban rail transit systems,” Journal of Planning Literature 11(1): 17-30.

Knaap, G.J., 1985. "The price effects of urban growth boundaries in metropolitan Portland, Oregon,” Land Economics 61(1):26-35.

Knaap, G.J., 2001. "The urban growth boundary in Metropolitan Portland, Oregon: Research, rhetoric, and reality,” American Planning Association, PAS memo.

McDonald, J.F. and C.I. Osuji, 1995. "The effect of anticipated transportation improvements on residential land values," Regional Science and Urban Economics 25: 261-78.

Mieszkowski, P. and E. Mills, 1993. “The causes of metropolitan suburbanization,” Journal of Economic Perspectives 7(3), 135-47.

Mitchel, R. and C. Rapkin, 1954. Urban Traffic: A Function of Land Use. New York: Columbia University Press.

Nelson, A.C., 1986. "Using land markets to evaluate urban containment programs," Journal of the American Planning Association, 52(2): 156-71.

Pendall, R., 1999. “Do land-use controls cause sprawl?” Environment and Planning B: Planning and Design 26: 555-571.

Pendall, R. 2000. "Local land-use regulation and the chain of exclusion," Journal of the American Planning Association 66: 125-142. 
Pendall, R., 2001. "Municipal plans, state mandates, and property rights: Lessons from Maine,” Journal of Planning Education and Research 21(2): 154-165.

Sohn, J. and M. Howland, Forthcoming. "Has Maryland's priority funding areas initiative constrained the expansion of water and sewer investments?” Journal of the American Planning Association, in press.

Sohn, J. and G. Knaap, 2002. Does the job creation tax credit program in Maryland induce spatial employment growth or redistribution? Presented at the 49th Annual North American Meeting of the Regional Science Association International.

Song, Y. and G. J. Knaap, 2004. "Measuring urban form: is Portland winning the battle against urban sprawl?” Journal of the American Planning Association 70(2): 210 $-225$.

Southworth, M., 1997. "Walkable suburbs? An evaluation of neotraditional communities at the urban edge," Journal of American Planning Association 63: 28 - 44.

Talen, E., 1996. "Do plans get implemented? A review of evaluation in planning," Journal of Planning Literature 10(3):248-59.

Talen, E. and G.J. Knaap, 2003. "The implementation of smart growth principles: an empirical study of land use regulation in Illinois," Journal of Planning Education and Research 22(4): 345-359.

Transportation Center, University of Illinois at Chicago, 1998. Highways and Urban Decentralization. Chicago, IL: University of Illinois at Chicago. 